\title{
Cell death and cell protection genes determine the fate of pistils in maize
}

\author{
Alejandro Calderon-Urrea* and Stephen L. Dellaporta \\ Department of Molecular, Cellular and Developmental Biology, Yale University, New Haven, CT 06520-8104, USA \\ *Present address: Department of Biology, California State University-Fresno, Fresno, CA 93740, USA \\ ‡Author for correspondence (e-mail: stephen.dellaporta@yale.edu) \\ Accepted 12 November 1998; published on WWW 7 January 1999
}

\section{SUMMARY}

The formation of unisexual flowers in maize requires the selective elimination and sexual maturation of floral organs in an initially bisexual floral meristem. Elimination of pistil primordia occurs in the primary and secondary florets of the tassel spikelets, and in the secondary florets of ear spikelets. Ill-fated pistil cells undergo a cell death process associated with nuclear degeneration in a specific spatialtemporal pattern that begins in the subepidermis, eventually aborting the entire organ. The sex determination genes tasselseed 1 and tasselseed 2 are required for death of pistil cells. tasselseed1 is required for the accumulation of
TASSELSEED2 mRNA in pistil cells. All pistil primordia express TASSELSEED2 RNA but functional pistils found in ear spikelets are protected from cell death by the action of the silkless 1 gene. silkless 1 blocks tasselseed-induced cell death in the pistil primordia of primary ear florets. A model is proposed for the control of pistil fate by the action of the $t$ 1-ts2-sk1 pathway.

Key words: tasselseed, Flower development, Cell death signaling, Maize

\section{INTRODUCTION}

Sex determination in maize involves the formation of unisexual flowers (called florets in grasses) through the selective elimination of unnecessary floral organs. The basic unit of the maize inflorescence is the spikelet that consists of two leaf-like subtending glumes enclosing two florets (referred to as the primary and secondary floret). During spikelet maturation, each floret meristem produces one lemma, one palea, three lodicules, three stamens and one pistil primordium (Fig. $1 \mathrm{~A}, \mathrm{~B}, \mathrm{D})$. After reaching this bisexual stage, the fate of a floret is decided by its location in either the tassel or ear, and its position within the spikelet. In the tassel, pistil primordia are eliminated from both the primary and secondary florets (Fig. 1A top, B,C); a cell death process associated with cellular vacuolation and the breakdown of free ribosomes and organelles (Cheng et al., 1983). Pistil elimination requires functions encoded by the tasselseed ( $t s$ ) genes, specifically $t s 1$ and $t s 2$ (reviewed by Dellaporta and Calderon-Urrea, 1994; Irish, 1996). In tsl-Reference ( $t s 1-R)$ or ts2-Reference ( $t s 2-R$ ) mutant plants, primary and secondary pistils in tassel spikelets fail to abort and stamen primordia are arrested, resulting in a sexual conversion of the tassel from staminate to pistillate. The ts 2 gene has been cloned and shown to be expressed in subepidermal pistil cells of developing male florets in the tassel (DeLong et al., 1993). The putative TS2 protein encodes a protein with similarity to short-chain alcohol dehydrogenases with signature motifs of hydroxysteroid dehydrogenases.

A more complex pattern characterizes the fate of floral organs in the spikelets of the ear inflorescence. Most often, mature ear spikelets contain a solitary pistillate floret resulting from the arrest of all stamen primordia and the selective elimination of the secondary pistil primordium (Fig. 1A bottom, D,E). Consequently, the primary floret of ear spikelets usually contains the only functional pistil found in most lines of maize. The tasselseed pathway is also required for the process of pistil elimination in secondary florets of the ear spikelets. In the $t s l-R$ and $t s 2-R$ mutant plants, secondary pistils fail to abort resulting in double pistillate florets in ear spikelets. The stamen arrest process in ear spikelets is not affected by mutations in $t s 1$ or $t s 2$.

Here we show that the elimination of pistils in maize is a developmentally staged cell death process associated with nuclear degeneration. Pistil cell death begins in subepidermal cells of the pistil primordia and requires ts 2 activity. We also show that TS2 RNA accumulation is regulated by $t s 1$, and that all pistil primordia express TS2 RNA but the functional primary pistils that develop in ear spikelets are protected from tasselseed-induced cell death by the action of the silkless 1 gene. The combined action of ts1-ts2-sk1 accounts for the developmental fate of pistils in the maize sex determination pathway.

\section{MATERIALS AND METHODS}

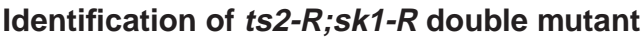

Homozygous $t s 2-R$ plants were crossed as females to homozygous $s k 1-R$ males and $F_{1}$ progeny self-pollinated. In subsequent generations, plants were sib-mated and the double mutant genotype was confirmed by the use of a co-dominant $t s 2$-linked microsatellite 
located $1.5 \mathrm{~kb}$ downstream from the $3^{\prime}$ end of the $t s 2$ gene. Primers to amplify the microsatellite are 5'TGACGGACGTGGATCGCTTCAC3' and 5'AGCAGGCAGCAGGTCAGCAGCG3'. The $t s 2$ mutant plants were identified by the presence of a single 120 bp band and absence of the $100 \mathrm{bp}$ fragment associated with the $T s 2$ allele from the W22 inbred (our unpublished results). These $t s 2$ mutant plants were crossed with $s k 1-R$ pollen; $s k 1-R$ non-complementation in these testcross progeny indicated the $t s 2$ mutant parent was also homozygous for the $s k 1$ mutation. As previously reported (Irish et al., 1994; Jones, 1932), double mutant plants (ts2-R; skl-R) showed complete epistasis of $t s 2-R$ to $s k 1-R$ in the ear and incomplete epistasis in the tassel (the distal portion of predominantly pistillate tassel remained staminate). This partial epistasis allowed selfing of these double mutant plants for two generations. In advanced generations, the partial epistasis phenotype was replaced by complete epistasis of $t s 2-R$ to $s k 1-R$ in both tassel and ear.

\section{Cytological techniques}

The formaldehyde tissue fixation, paraffin embedding and microtomy were essentially as described by Jackson (1991) except that Hemo-De (Fisher, Scientific Co.) was substituted for Histoclear (Agar Aids Ltd.), $8 \mu \mathrm{m}$ sections were used for all staining, and tissue sections were dried overnight onto ProbeOn Plus microscope slides (Fisher Scientific Co.). Nuclear loss assays were performed by deparaffinizing and rehydrating tissue sections according to the method of Jackson (1991). Slides were then incubated in a $0.3 \mathrm{mM}$ solution of 4',6-diamidine-2-phenylindole dihydrochloride (DAPI; Boehringer Mannheim) for 5 minutes at room temperature. After incubations, slides were washed in PBS and mounted in $70 \%$ glycerol, $30 \%$ PBS.

\section{Microscopy and photography}

Sections were examined using a Zeiss Axiophot photomicroscope (Carl Zeiss, NY). Sections were observed and photographed on Ektachrome Elite 400 film, using UV light. The filter used for observations was D460/50 (31000M from Chroma Technology Corp.). $35 \mathrm{~mm}$ slides were digitized using a Polaroid SprintScan 35 slide scanner (Polaroid Corp.). Composites figures were generated and labeled using Adobe Photoshop 4.0 (Adobe Systems Incorporated).

\section{Plasmid templates and riboprobes}

Plasmid DNA was prepared using Qiagen 100 columns (Qiagen Inc.) following the manufacturer's instructions. DNA templates for TS2 sense and antisense riboprobes were linearized by digesting plasmid pADL171 and pADL170 (DeLong et al., 1993), respectively, with EcoRI. In vitro transcription reactions using T7 or T3 RNA polymerase and 11-digoxigenin-dUTP (Boehringer Mannheim), riboprobe DNase treatment, and hydrolysis was according to the manufacturer's instructions.

\section{In situ hybridization}

Tissue sections were pretreated for in situ hybridizations essentially as described by Jackson (1991). Sections were hybridized as previously described (Langdale, 1993) with the exception that the final concentration of riboprobe was adjusted to $10 \mathrm{ng} / \mathrm{ml} / \mathrm{kb}$ and hybridization was performed at $62^{\circ} \mathrm{C}$ overnight. Procedures for hybridization, posthybridization incubations, and antibody detection were obtained from Bruce Veit (Massey University, New Zealand; personal communication). Nuclear degeneration assays were performed by incubating in a $75 \mathrm{mM}$ solution of propidium iodide (Sigma Co.) for 10 minutes at $4^{\circ} \mathrm{C}$. After incubations, slides were washed in PBS and mounted in 70\% glycerol, 30\% PBS. Sections were counterstained with Calcofluor and examined and documented using a Zeiss Axiophot photomicroscope (Carl Zeiss, NY). Sections were photographed on Ektachrome 160T film with simultaneous illumination under bright and UV-fluorescent light. Propidium iodide stained sections were observed and photographed using the filter
D605/55 (31002M from Chroma Technology Corp.) and Ektachrome Elite 400 film.

\section{RT-PCR analysis}

Total RNA from tassels $15 \mathrm{~mm}$ in length was isolated using the TRIzol Reagent (Gibco BRL), according to the manufacturer's instructions. RNA was treated with RNase-free DNase I (Boehringer Mannheim) for 20 minutes at $37^{\circ} \mathrm{C}$. First strand cDNA synthesis was performed on $5 \mu \mathrm{g}$ of total RNA by the RACE procedure (Frohman et al., 1988) modified as follows: 200 units of SuperScript II reverse transcriptase (Gibco BRL) were added to the first strand reaction mix and synthesis was carried out at $42^{\circ} \mathrm{C}$ for 2 hours. The reaction was diluted to a final volume of $100 \mu \mathrm{l}$ with $\mathrm{dH} 20.5 \mu \mathrm{l}$ of the diluted reaction mix was used as template in a PCR amplification reaction containing an adapter primer (Frohman et al., 1988) and a TS2-specific primer (5'ATGCTCATCAACGCCTGGCG3'). The conditions for amplification were: $94^{\circ} \mathrm{C}, 2$ minutes; then 30 cycles of $94^{\circ} \mathrm{C}, 30$ seconds; $60^{\circ} \mathrm{C}, 30$ seconds; $72^{\circ} \mathrm{C}, 30$ seconds. The reaction was then extended at $72^{\circ} \mathrm{C}$ for 15 minutes. PCR products were resolved on a $1 \%$ agarose gel in TAE buffer. Fragments were transferred in $0.4 \mathrm{M}$ $\mathrm{NaOH}$ to Zeta-Probe GT (Bio-Rad) membranes, and hybridized to TS2 cDNA probe as described by Dellaporta and Moreno (1993). Each reaction was also subject to PCR amplification under identical conditions using actin gene primers P213 (5'CATGAGGCCACGTACAACTCCATC3') and P214 (5'TCATACTCTCCCTTGGAGATCCAC3').

\section{RESULTS}

\section{Stage-specific cell death during pistil abortion}

We examined cellular changes associated with pistil elimination by analyzing sections of paraffin-embedded immature florets with the fluorescent DNA stain 4', 6diamidine-2-phenylindole-dihydrochloride (DAPI). We refer to the relative positions of the florets as the T1 (primary) and T2 (secondary) florets of the tassel spikelets; and the E1 (primary) and E2 (secondary) florets of the ear spikelets. Features of maize inflorescence development allowed us to analyze several stages of unisexual spikelet formation within a single inflorescence. Spikelet maturation proceeds in an acropetal fashion with more advanced spikelets at the base than at the tip of the growing inflorescence. A second developmental asynchrony exists within each maturing spikelet with primary florets more developmentally advanced than secondary ones.

Regardless of their ultimate destiny, immature bisexual florets were observed to have brightly staining nuclei, indicative of nuclear DNA integrity (Fig. 2A,E). As tassel spikelets matured, however, nuclear loss, as judged by greatly diminished DAPI fluorescence, was observed in subepidermal cells of T1 pistils (Fig. 2B,C). The pattern of loss occurred in a specific spatial and temporal pattern within the degenerating pistil. The earliest indications of nuclear DNA loss began in just a few subepidermal cells within the central region of the pistil at a developmental stage that coincided with the formation of the gynoecial ridge (as shown for T1 pistils in Fig. 2B). As spikelets matured, a greater region of the subepidermis lost nuclei until all, or nearly all, subepidermal nuclear fluorescence was missing (Fig. 2C). Even though a large number of subepidermal cells were affected, overlying epidermal cells had brightly staining nuclei until late in the pistil abortion process when the entire pistil collapsed due to a loss of structural integrity (not shown). Within individual 
A
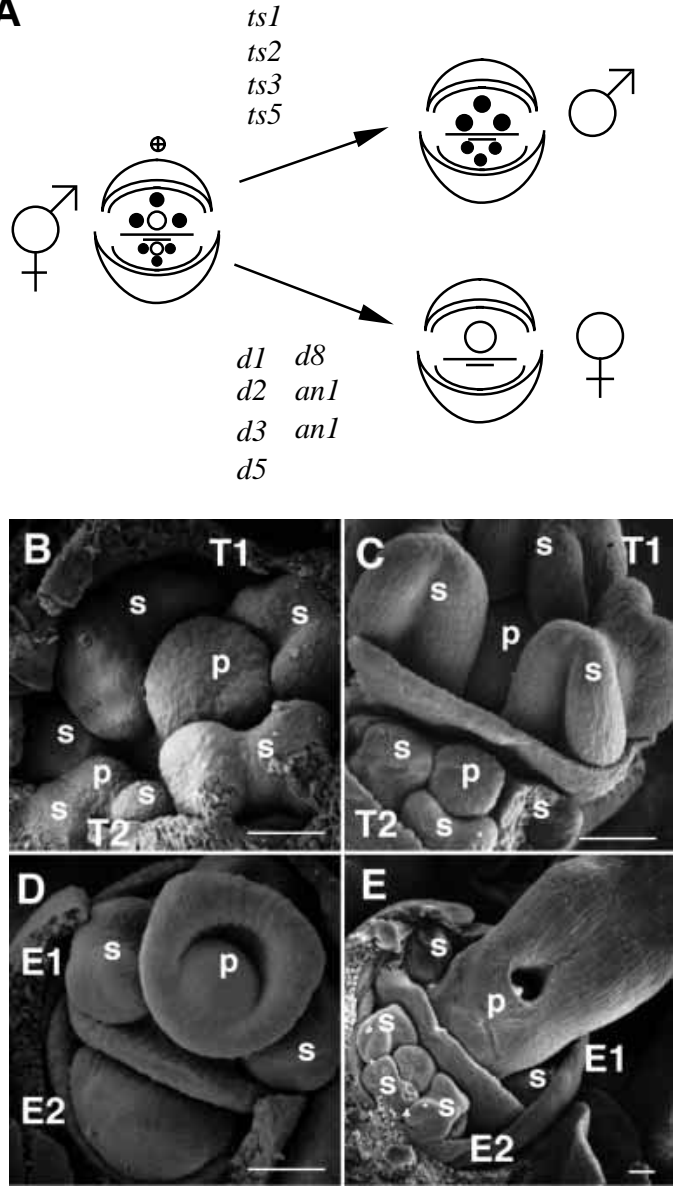

Fig. 1. Transition from bisexual to unisexual florets. (A) Maize floral diagram of an immature spikelet containing two bisexual floral meristems (left) and mature spikelets converted either to a tassel spikelet containing two staminate florets (top, right) or to an ear spikelet containing a solitary pistillate floret (bottom, right) by the action of the genes indicated. The tasselseed ( $t s)$ 1, 2, 3 and 5 genes promote pistil abortion. The later two genes are defined by dominant mutations. $t s 1$ and $t s 2$ are also required for abortion of pistils in the secondary ear florets. The $d w a r f(d) 1,2,3,5$ and 8, and anther earl (anl) genes promote stamen abortion and feminization. The $d 8$ gene is defined by a dominant mutation. silkless 1 (skl) is required for development of the primary pistil (Modified from Dellaporta and Calderon-Urrea, 1994 with permission from AAAS). The floral diagrams shows pistils $(\mathrm{O})$, stamen initials $(\bullet)$, palea $(-)$, lemma $(\cap)$, and glumes $(\mathcal{)})$ when present; lodicules are not shown. (B,C) SEM analysis of tassel staminate spikelet development. (B) Bisexual stage of primary florets at which time pistil and stamen initials are similar in size; secondary floral organs have begun to initiate. After the bisexual stage, a gynoecial ridge forms and primary pistils begin to abort while stamen initials continue to develop. (C) Unisexual stage of primary florets at which time pistil abortion is nearly complete and stamen maturation continues; the gynoecial ridge formation and pistil abortion has begun in the secondary floret. (D,E) SEM analysis of pistillate spikelet development. (D) Bisexual stage of the primary ear floret at which time pistil and stamen initials are similar in size. The secondary floral primordium has no clearly distinguishable organs. After the bisexual stage, primary pistil maturation continues and stamen initials become arrested; secondary floral organs become evident. (E) Unisexual stage of the primary floret showing the maturing primary pistil with elongating style. Primary and secondary stamen initials are arrested; secondary pistils form a gynoecial ridge and begin to abort. T1, tassel primary floret; T2 tassel secondary floret; E1, ear primary floret; E2, ear secondary floret; P, pistil; S, stamen. Scale bars, $50 \mu \mathrm{m}$. tassel spikelets, there was a delay in the degeneration of $\mathrm{T} 2$ pistils with respect to T1 pistils. Nuclear DNA loss in T2 pistils began when T1 pistil degeneration was well underway, and in a similar subepidermal pattern (not shown). Nuclear loss observed in T2 pistils began in subepidermal cells at a stage of pistil maturation equivalent to that seen when $\mathrm{T} 1$ pistil nuclei degenerated (i.e. during formation of the gynoecial ridge). In ear spikelets, no signs of cell death or nuclear loss were observed in wild-type E1 pistils (Fig. 2E-G). E2 pistils, however, showed nuclear loss in a spatial and temporal pattern similar to T1 and T2 pistils (Fig. 2F,G). Analogous results to the data reported here were obtained with the DNA stains propidium iodine (an example is shown in Fig. 3F) and toluidine blue (data not shown).

\section{tasselseed2 is required for pistil cell death}

The $t s 2-R$ mutation blocks the process of pistil elimination in both tassel and secondary ear florets. In contrast to pistil abortion in wild-type plants, the T1, T2 and E2 pistils of $t s 2$ $R$ plants reach sexual maturity and are functional. Hence, loss of $t s 2$ activity prevents all pistil elimination in the maize plant. We examined mutant tassel and ear spikelets by DAPI staining to determine how the $t s 2-R$ mutation interferes with the pistil cell death process. In $t s 2-R$ mutant tassels, the integrity of nuclei in cells in both $\mathrm{T} 1$ and $\mathrm{T} 2$ pistils was maintained throughout spikelet maturation, as judged by uniform distribution of DAPI staining throughout the epidermal and subepidermal cells (Fig. 2D). Likewise, in $t s 2-R$ ear spikelets, there was no evidence for nuclear loss in E2 pistils (Fig. 2H). These results indicate that the pistil cell death process associated with nuclear loss requires a functional $t s 2$ gene.

The tasselseed 2 gene of maize is expressed in T1 pistils prior to cellular degeneration (DeLong et al., 1993). To determine whether $t s 2$ expression coincided with nuclear loss and cell death in other pistils, we followed its expression, by in situ hybridization, in both tassel and ear spikelets (Fig. 3). In tassel spikelets, $t s 2$ expression was first detected in $\mathrm{T} 1$ pistil cells shortly after reaching the bisexual stage (Fig. 3A) and at a similar stage of floret maturation in T2 pistils (Fig. 3B). Cellular expression of $t s 2$ coincided with the loss of nuclei, as judged by TS 2 mRNA in situ hybridization and counterstaining tissue sections with propidium iodine (Fig. 3E,F). In ear spikelets $t s 2$ expression was detected in the subepidermal cells of both E1 and E2 pistil primordia (Fig. 3C,D). E1 expression was unexpected because these pistils are functional and are not eliminated during spikelet maturation.

\section{tasselseed 1 regulates expression of tasselseed 2}

The tasselseed 1 locus is defined by a recessive mutation ( $t s 1$ $R$ ) which transforms the staminate florets of the tassel into pistillate ones (Emerson, 1920). Mutant $t s l-R$ plants have a phenotype indistinguishable from $t s 2-R$ plants - tassel and ear spikelets contain double pistillate florets. The similarity of $t s 1$ $R$ and $t s 2-R$ mutant phenotypes suggests that these genes may lie within the same sex determination pathway. Formal genetic epistasis analysis is not possible due to the similarity of $t s l-R$ and $t s 2-R$ mutant phenotypes. Therefore, to address this possibility, we examined $t s 2$ expression in $t s 1-R$ mutant plants by in situ hybridization (Fig. 4). $t s 2$ expression was undetected in $t s 1-R$ mutant tassel pistils (Fig. 4A,C) at a developmental stage when expression was expected in wild-type pistils (Fig. 
Fig. 2. Nuclear loss and cell death in wild-type and mutant tassels and ears. DAPI staining of longitudinal sections wild-type tassel spikelets (A-C) showing evidence for nuclear loss (arrowheads) in subepidermal pistil cells of the T1 floret. Subepidermal nuclear loss is also seen in transverse sections of the wild-type E2 pistils as ear spikelets mature (E-G). Longitudinal sections showing the absence of nuclear loss at late stage of pistil maturation of the $t s 2-R$ mutant tassel spikelets (D), and in transverse sections of $t s 2-R$ ear spikelets $(\mathrm{H})$. See legend of Fig. 1 for abbreviations. Arrowheads in D-H indicate pistil primordia. Scale bars, $50 \mu \mathrm{m}$.
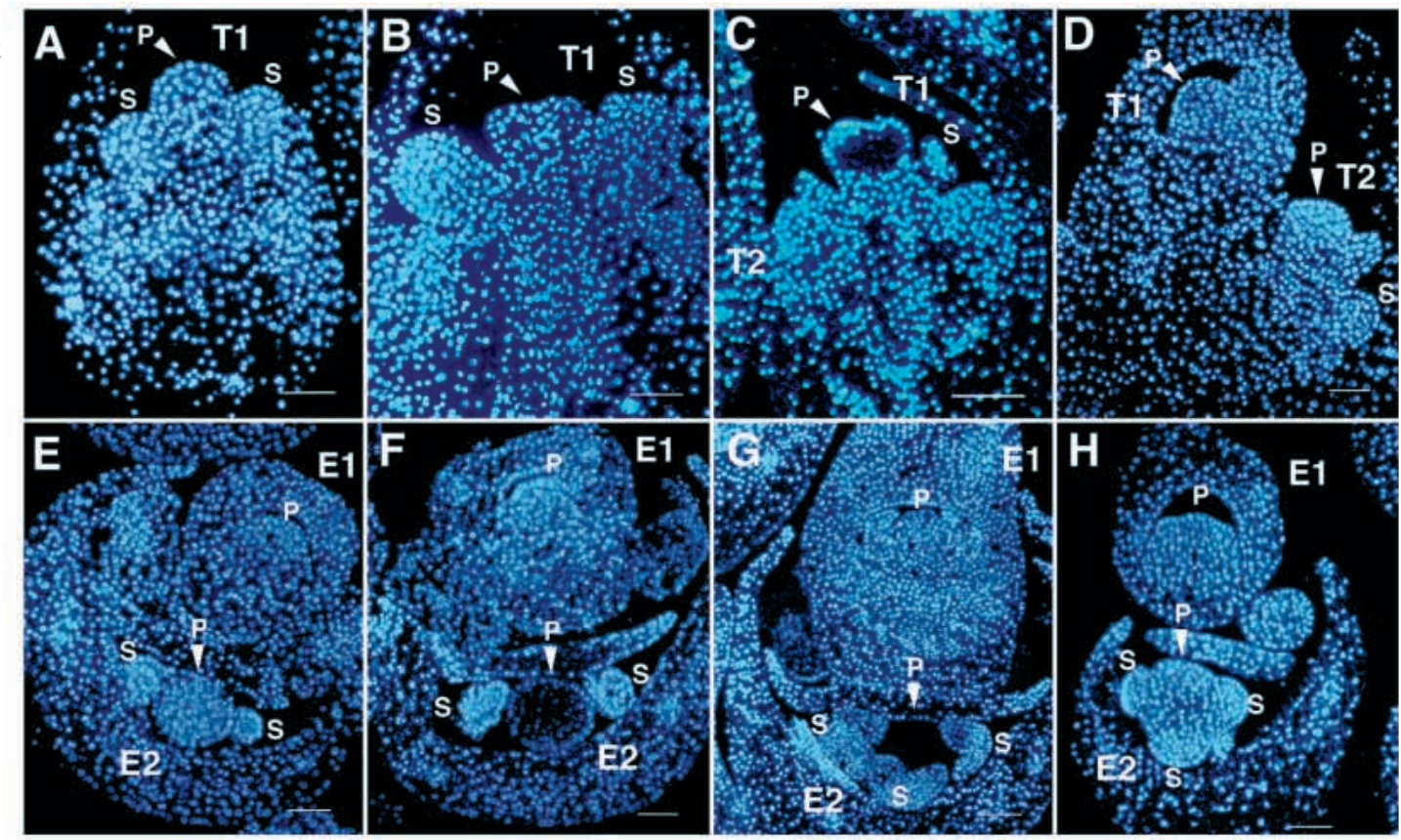

4B,D). A similar result was seen in E2 pistils (not shown). These results suggest that TS1 action was required for TS2 RNA accumulation.

To confirm these results, RT-PCR analysis for TS2 mRNA was performed on RNA extracted from wild type, $t s 2-R$ and $t s 1-R$ tassels (Fig. 5). The expected 455 bp amplification product was seen in wild-type tassel cDNA (Fig. 5A, lane 5), but nearly absent in $t s 1-R$ (lane 7) and $t s 2-R$ (lane 9) tassel cDNA. A minute amount of a TS2 amplification product was detected in the $t s 1-R$ tassels after long exposures of the autoradiograph. Based on the relative intensities of these products, we estimate that $t s 1-R$ tassels must contain at least 100-fold less TS2 mRNA. As a control for the quality and quantity of cDNA used in each PCR reaction, actin cDNA was co-amplified using gene-specific primers. Fig. 5B shows that amplification of an actin cDNA product was uniform with each template, indicating that the cDNA quality and quantity used in each reaction was roughly equivalent. These results eliminate the possibility that the previous in situ data was due to precocious or delayed expression of $t s 2$ in the $t s 1-R$ mutant since RT-PCR analysis was done on the entire inflorescence cDNA representing a continuum of spikelet development. Taken together, these in situ hybridization and RT-PCR data indicate that the tasselseedl gene regulates the synthesis or accumulation of TS2 mRNA in pistil cells.

\section{silkless1 protects pistils from tasselseed-induced cell death}

The expression of $t s 2$ in the functional E1 pistil appears to conflict with its role as a mediator of cell death. This apparent contradiction may indicate that $t s 2$ expression is an insufficient indicator of cell death, or that, unlike all other pistils, E1 pistils are protected from tasselseed-induced cell death. To address this issue, we examined the fate of E1 pistils in plants homozygous for the recessive silkless 1 mutation $(s k 1-R)$ in which E1 pistils are non-functional (Jones, 1925). Previous studies indicated that the ear phenotype of the $t s 2 \mathrm{skl}$ double mutant was similar to that of the $t s 2$ single mutant, while the tassel had predominantly staminate florets with pistillate and perfect florets at the base of the tassel (Irish et al., 1994; Jones, 1934). These studies concluded partial epistasis between the $t s 2$ and $s k 1$. We noted that after self pollinating double mutant plants $(s k 1-R ; t s 2-R)$ for two generations, the $t s 2-R$ mutation showed complete epistasis to $s k l-R$. The partial epistasis may be due to incomplete expressivity of one or both mutations in heterogeneous genetics backgrounds.

In $s k 1-R$ ears, we found that the failure of E1 pistils to develop involves stage-specific cell death with features indistinguishable from tasselseed-induced abortion of other pistils. For instance, loss of nuclei in $s k 1-R$ E1 pistil cells occurred in the subepidermal cells of the pistil, leaving epidermal cells relatively intact (Fig. 6A). Subepidermal $t s 2$ expression coincided with the timing of nuclear degeneration and cell death in $s k 1-R \mathrm{E} 1$ pistils (Fig. 6B) suggesting that loss of $s k l$ activity does not interfere with the synthesis or accumulation of TS2 RNA. Asynchrony in the initiation of subepidermal cell death in E1 and E2 pistils was similar to that seen in tassel spikelets (not shown). These studies demonstrate that E1 pistil abortion in $s k 1-R$ mutant plants occurs in a similar spatial and temporal pattern as during tasselseed-induced cell death of other pistils. Taken together, the pattern of E1 pistil cell death in $s k 1-R$ mutants, $t s 2$ expression in E1 pistils, and the double mutant $t s 2-R ; s k 1-R$ phenotype all indicate that $s k 1$ activity is required to protect E1 pistils from tasselseedmediated cell death.

\section{DISCUSSION}

\section{Pistil elimination is a developmentally programmed and tasselseed-mediated cell death process}

In both ear and tassel florets, the elimination of pistils involves a mechanism associated with loss of nuclear DNA as one of its prominent and early characteristics. Our results indicate that 
pistil cell death, as judged by nuclear DNA loss, begins at a particular stage of floret maturation, just as the gynoecial ridge is beginning to form, and in a specific spatial pattern initially restricted to only subepidermal cells. In the tassel, as spikelets mature, the T1 pistil primordium degenerates, later followed by degeneration of the developmentally delayed neighboring T2 pistil. The gradient of spikelet maturation on the inflorescence axis and the asynchrony of the maturation of primary and secondary florets within each spikelet result in two overlapping acropetal waves of pistil cell death. The first wave, acting on the primary pistils, is followed by a second delayed wave, acting on the secondary pistils. This pattern of cell death strongly argues that cell death is developmentally programmed in maize pistils.

The observation that most subepidermal nuclei were lost

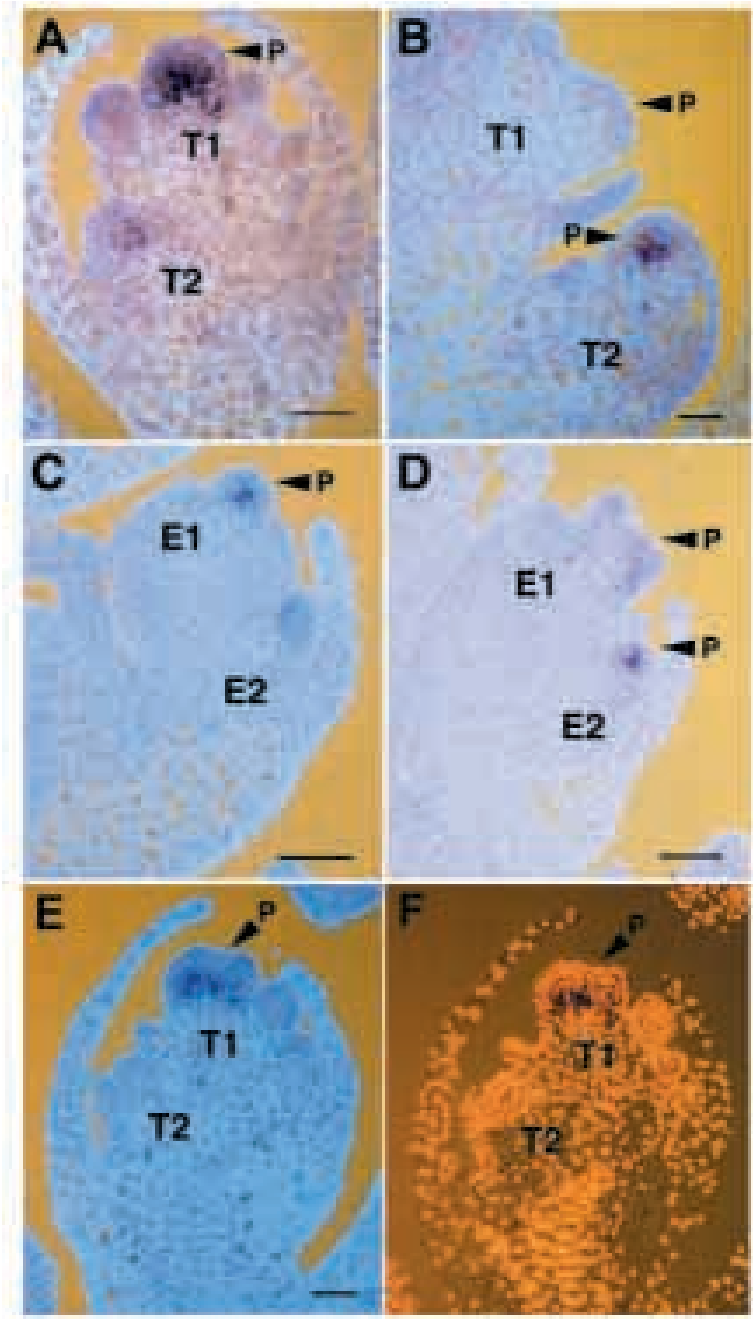

Fig. 3. TS2 in situ hybridization in wild-type tassel and ear spikelets. Serial sections were hybridized with a TS2 antisense (A-D) and sense probes (not shown); no expression was detected with a TS2 sense probe. Tassel spikelets $(\mathrm{A}, \mathrm{B})$ and ear spikelets $(\mathrm{C}, \mathrm{D})$ are shown. TS2 expression is detected in T1 (A) and T2 (B) pistils of tassel spikelets, and in E1 (C) and E2 (D) pistils of ear spikelets. See legend to Fig. 1 for abbreviations. $\mathrm{E}$ and $\mathrm{F}$ are the same section first hybridized with TS2 antisense probe (E) then counterstained with propidium iodide $(\mathrm{F})$ to visualize the nuclear loss pattern. Note the loss of nuclei in cells at the site of TS2 expression. See legend of Fig. 1 for abbreviations. Scale bars, $50 \mu \mathrm{m}$. while overlying epidermal cells continued to show good nuclear integrity suggests that the mechanism of pistil cell death may function cell-autonomously. These complex patterns of pistil abortion suggest that the cell death signaling process may be self-initiating, rather than mediated by an exogenous signal perceived by all pistils. Alternatively, an exogenous signal may exist but its perception may be delayed until the pistil cells reach a certain state of competency.

\section{tasselseed genes are required for cell death}

Genetic and molecular evidence shows that $t s 2$ is required for pistil elimination in both tassel and ear spikelets. $t s 2$ was expressed in pistil cells coincident with loss of nuclear integrity. $t s 2$ expression and loss of nuclear integrity, as judged by loss of DAPI (and propidium iodide) staining, were the first indications of cell death in pistils. Finally, all pistil cell death was absent in both ears and tassels of $t s 2-R$ mutant plants. The coincident expression of $t s 2$ in degenerating cells and its mutant phenotype provide strong evidence that $t s 2$ is a mediator (direct or indirect) of cell death.

Yet, it is still not clear how the $t s 2$ gene product may be functioning in a cell death pathway. On the basis of its similarity to short-chain alcohol dehydrogenases, especially to hydroxysteroid dehydrogenases (DeLong et al., 1993), two possibilities come to mind. The $t s 2$ product may metabolize a substrate, perhaps a steroid, required for cell viability.

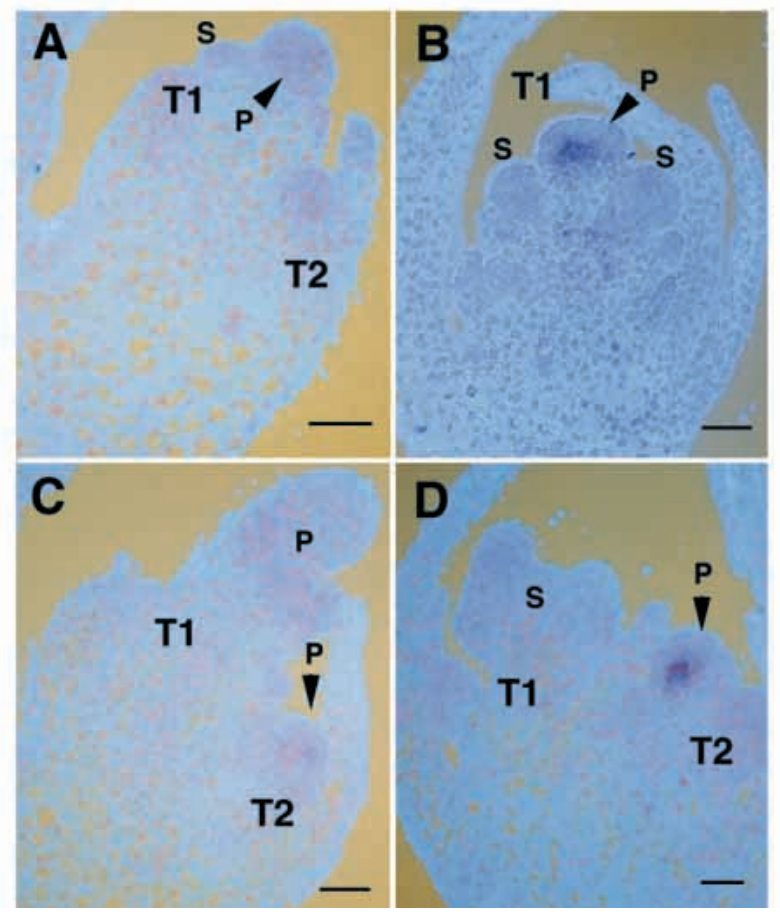

Fig. 4. In situ hybridization analysis of TS2 mRNA expression in $t s 1-R$ and wild-type tassels. Sections of $t s 1-R$ mutant $(\mathrm{A}, \mathrm{C})$ and wildtype (B,D) tassel spikelets were hybridized to TS2 antisense probe. As a positive control for the quality of tissue sections, serial sections were hybridized to an antisense probe of the maize MADS gene zag1, a homologue of the Arabidopsis AGAMOUS gene, that is expressed in both stamen and pistils primordia (Schmidt et al., 1993) (not shown). See legend to Fig. 1 for abbreviations. Scale bars, $50 \mu \mathrm{m}$. 
A

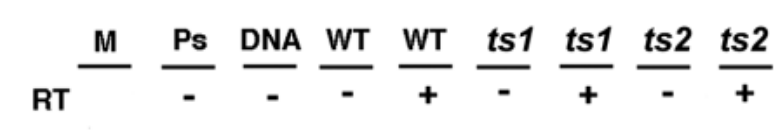

$492-$

$123-$

\section{B}

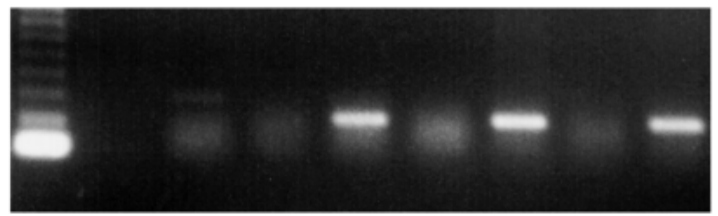

Fig. 5. RT-PCR analysis of TS2 mRNA expression in $t s 1-R$ and wildtype tassels. (A) $t s 2$-specific and RACE primers alone (lane 2) or other substrates indicated (lanes 3-9) were subjected to PCR amplification either with (+) or without (-) the reverse transcriptase (RT) step. PCR products were subjected to Southern blot analysis using a ts 2 cDNA probe. (B) Ethidium bromide stained gel after PCR amplification of substrates as in A using actin-specific primers to control for cDNA quality. Abbreviations: M, 123 base pair ladder (Gibco, BRL); RT, reverse transcriptase treatment; Ps, primers alone; DNA, maize genomic DNA; WT, wild-type tassel cDNA; $t s 1, t s 1-R$ tassel cDNA; $t s 2, t s 2-R$ tassel cDNA.

Alternatively, TS2 action may result in the formation of a signaling molecule that activates a cell death response. For instance, several signaling molecules are known to induce the process of apoptotic cell death in animal cells (Roy et al., 1992; Wyllie et al., 1980). There is no evidence, however, that the process of pistil cell death is related, in any way, to apoptosis.

Our data suggests a functional role for $t s l$ in the cell death process as a regulator of $t s 2$ expression. The most parsimonious explanation for these results is that the $t s 1$ gene product may be a transcriptional regulator of the $t s 2$ gene. Another possible mode of action is that the regulation of $t s 2$ by $t s I$ is an indirect one. For instance, other factors that directly

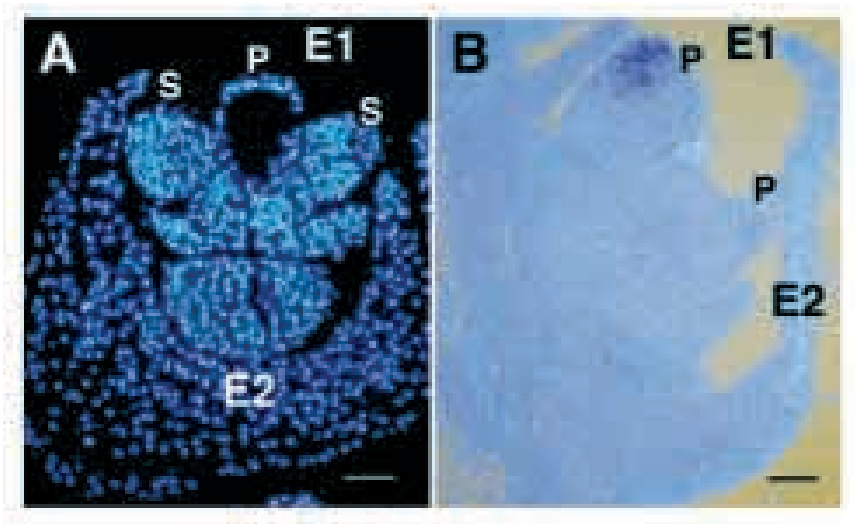

Fig. 6. Analysis of cell death and TS2 expression in $s k 1-R$ ear spikelets. (A) DAPI staining of longitudinal sections of $s k 1-R$ ear spikelets showing subepidermal nuclear loss in E1 pistils (P). (B) In situ hybridization with TS2 antisense probe to sections of $s k 1-R$ ear spikelets. In the $s k 1-R t s 2-R$ double mutants, no sign of nuclear loss is seen in ear or tassel spikelets (not shown). See legend to Fig. 1 for abbreviations. Scale bars, $50 \mu \mathrm{m}$.
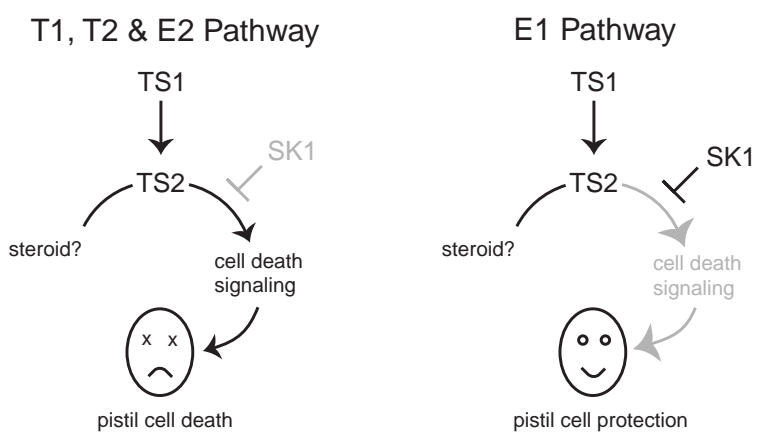

Fig. 7. Model pathway for pistil fate in maize sex determination. In primary and secondary florets in the tassel (T1 and T2), and in secondary ear florets (E2) pistil fate is controlled by the action of tasselseed genes. TS2 acts on an unknown substrate, possibly a steroid, to mediate a cell-autonomous cell death response. The function of TS 1 is to promote $t s 2$ expression. It is not known whether TS1 activates genes needed for cell death signaling in addition to $t s 2$. In primary ear florets (E1) pistils are protected from tasselseedmediated cell death by $s k 1$ action. SK1 may protect pistils by directly interfering with TS2 activity or by blocking a downstream step in the cell death response. This model predicts that $s k 1$ will be differentially expressed or activated in E1 pistils.

regulate $t s 2$ expression may be under $t s 1$ control, or that the ts 1 gene product may be required for the stability of the TS2 mRNA. The cloning of $t s 1$ should help elucidate its role in the sex determination process.

\section{Role of silkless 1 in sex determination}

On the basis of epistasis results (Jones, 1932, 1934), it has previously been proposed that $s k 1$ suppresses $t s 2$ 's potential to suppress silk (pistil) development (Veit et al., 1993). Our data show that $s k 1$ specifically protects E1 pistils from tasselseedmediated cell death although the mechanism of $s k 1$ protection is unknown. Several examples of cell protection genes are known in animal systems. Protection from cell death by direct inactivation of cell death factors is thought to occur in blocking apoptosis. For instance, the ICE/CED3 family of programmed cell death factors in animals are required for apoptotic cell death (reviewed by Martin and Green, 1995; Steller, 1995). The prototypes of this family of cysteine proteases, called caspases, are ICE and CED3 (Alnemri et al., 1996). A protein of baculoviruses (i.e. p35) has been shown to block ICE/CED3induced apoptotic cell death by forming stable inactive complexes (Bump et al., 1995). In C. elegans, the ced 3 and ced4 gene functions are required in cells undergoing programmed cell death (reviewed by Ellis et al., 1991). The ced 9 gene, a member of the same gene family as the human proto-oncogene BCL-2 (Hengartner, 1995; Hengartner et al., 1992), protects against ced3- and ced4-induced cell death. The CED4 protein binds in vitro to CED9 (Spector et al., 1997; Wu et al., 1997) and, after interaction, the CED4/CED9 complex localizes primarily to the membrane fractions in the cytoplasm of mammalian 293T cells (Wu et al., 1997). CED4 can also bind CED3, both independently of and simultaneously with CED9 (Chinnaiyan et al., 1997). These results suggests a possible scenario for the regulation of cell death in animals in which CED9/BCL2, localized at the mitochondrial membrane, binds and modulates CED4 which in turn binds CED3/ICE 
caspases. If CED4 is not bound by CED9/BCL2, binding of CED3/ICE caspases by CED4 may activate them, leading to cell death (Goldstein, 1997).

In the case of $s k 1$, several possibilities are consistent with our results. For instance, the product of $s k 1$ may function in a fashion similar to anti-apoptotic proteins by directly complexing with the $t s 2$ gene product to prevent pistil cell death or it may interfere with a downstream step in a cell death signaling pathway. Also, similarly to CED3/CED4/CED9 cell death regulation, SK1 may function by binding and sequestering TS2, or other cell death factors, to an organelle compartment, thus preventing pistil cell death. To distinguish among these various mechanisms, the isolation of the $s k l$ gene, its product localization pattern and interaction, if any, with TS2 will be important to determine.

\section{A model for the control of pistil fate}

A model for the control of pistil fate by two alternative pathways is presented in Fig. 7 that is consistent with all available genetic and molecular observations. In this model, pistil fate is determined by the action of three genes: $t s 1, t s 2$, and $s k 1$; other genes may yet be discovered. Consistent with the inability to detect the TS2 mRNA in $t s l-R$ pistils, we propose that $t s 1$ is a positive regulator of $t s 2$ gene expression. TS2 action, either directly or indirectly, elicits a cell death response, presumably through the modification of an unknown substrate. This substrate may be related to steroids based on TS2 protein similarity to bacterial and mammalian hydroxysteroid dehydrogenases. To protect the functional E1 pistils, an alternative pathway is evoked involving the action of the cell protection gene skl required to block tasselseedinduced cell death signaling. skl may function directly to inactivate TS2 action or block a downstream effector of the TS2 signaling. A role for $s k 1$ in modulating the availability of a TS2 substrate is inconsistent with the wild-type tassel phenotype of $s k l-R$ mutant plants.

This model predicts that $s k l$ functions only in E1 and not in E2 or tassel pistils. The distribution of the $s k 1$ gene product may be extremely informative in this regard. Several other key issues, such as the biochemical function of the TS2 protein, its substrate and product, and the isolation of $s k 1$ and $t s 1$ will be of central importance in achieving a greater understanding of the sex determination process in maize.

We thank Robert Schmidt (UC-San Diego) and Bruce Veit (Massey University, New Zealand) for their generous advice and assistance with in situ hybridization techniques and protocols; Yashusi Yoshioka, Maria Moreno and Dadong Li (Yale University) for their helpful discussions and critical reading of the manuscript; and Scott Poethig (University of Pennsylvania) for his thoughts on SILKLESS1 function. This work was supported by a grant to S. L. D. from the National Institutes of Health (GM38148). A. C.-U. was supported by a graduate fellowship from Rockefeller Foundation.

\section{REFERENCES}

Alnemri, E. S., Livingston, D. J., Nicholson, D. W., Salvesen, G., Thornberry, N. A., Wong, W. W. and Yuan, J. (1996). Human ICE/CED3 protease nomenclature. Cell $\mathbf{8 7}, 171$.
Bump, N. J., Hackett, M., Hugunin, M., Seshagiri, S., Brady, K., Chen, P., Ferenz, C., Franklin, S., Ghayur, T., Li, P. et al. (1995). Inhibition of ice family proteases by baculovirus antiapoptotic protein p35. Science $\mathbf{2 6 9}$, 1885-1888.

Cheng, P. C., Gryson, R. I. and Walden, D. B. (1983). Organ initiation and the development of unisexual flowers in the tassel and ear of Zea mays. Am. J. Bot. 70, 450-462.

Chinnaiyan, A. M., O'Rourke, K., Lane, B. R. and Dixit, V. M. (1997). Interaction of CED-4 with CED-3 and CED-9: a molecular framework for cell death. Science 275, 1122-1126.

Dellaporta, S. L. and Calderon-Urrea, A. (1994). The sex determination process in maize. Science 266, 1501-1505.

Dellaporta, S. L. and Moreno, M. A. (1993). Southern blot hybridization. In The Maize Handbook, (ed. M. Freeling and V. Walbot), pp. 569-572. New York: Springer Verlag.

DeLong, A., Calderon-Urrea, A. and Dellaporta, S. L. (1993). Sex determination gene TASSELSEED2 of maize encodes a short-chain alcohol dehydrogenase required for stage-specific floral organ abortion. Cell 74, 757-768.

Ellis, R. E., Yuan, J. and Horvitz, H. R. (1991). Mechanisms and functions of cell death. Annu. Rev. Cell Biol. 7, 663-698.

Emerson, R. A. (1920). Heritable Characters of Maize II. Pistillated Flowered Maize Plants. J. Hered. 11, 65-76.

Frohman, M. A., Dush, M. K. and Matin, G. R. (1988). Rapid production of full-length cDNAs from rare transcrips: amplification using a single genespecific oligonucleotide primer. Proc. Natl. Acad. Sci. USA 85, 8998-9002.

Goldstein, P. (1997). Controlling cell death. Science 275, 1081-1082.

Hengartner, M. O. (1995). Life and death decisions - ced-9 and programmed cell death in caenorhabditis elegans. Science 270, 931-931.

Hengartner, M. O., Ellis, R. E. and Horvitz, H. R. (1992). Caenorhabditis elegans gene ced-9 protects cells from programmed cell death. Nature $\mathbf{3 5 6}$, 494-499.

Irish, E. E. (1996). Regulation of sex determination in maize. BioEssays 18, 363-369.

Irish, E. E., Langdale, J. A. and Nelson, T. M. (1994). Interactions between tassel seed genes and other sex determining genes in maize. Dev. Genet. 15, 155-171.

Jackson, D. (1991). In situ hybridization in plants. In Molecular Plant Pathology: A Practical Approach, vol. I (ed. S. J. Gurr, M. J. McPherson and D. J. Bowles), pp. 163-174. Oxford: Oxford University Press.

Jones, D. F. (1925). Heritable characters in maize. XXIII: Silkless. J. Heredity 16, 339-341.

Jones, D. F. (1932). The interaction of specific genes determining sex in dioecious maize. Proc. Sixth Int. Congress Genetics 2, 104-107.

Jones, D. F. (1934). Unisexual maize plants and their bearing on sex differentiation in other plants and in animals. Genetics 34, 552-567.

Langdale, J. A. (1993). In situ hybridization. In The Maize Handbook, (ed. M. Freeling and V. Walbot), pp. 165-180. New York: Springer Verlag.

Martin, S. J. and Green, D. R. (1995). Protease activation during apoptosis: death by a thousand cuts. Cell 82, 349-352.

Roy, C., Brown, D. L., Little, J. E., Valentine, B. K., Walker, P. R., Sikorska, M., Leblanc, J. and Chaly, N. (1992). The topoisomerase II inhibitor teniposide VM-26 induces apoptosis in unstimulated mature murine lynphocytes. Exp. Cell Res. 200, 416-424.

Schmidt, R. J., Veit, B., Mandel, M. A., Mena, M., Hake, S. and Yanofsky, M. F. (1993). Identification and molecular characterization of ZAG1, the maize homolog of the Arabidopsis floral homeotic gene AGAMOUS. Plant Cell 5, 729-737.

Spector, M. S., Desnoyers, S., Hoeppner, D. J. and Hengartner, M. O. (1997). Interaction between the C. elegans cell-death regulators CED-9 and CED-4. Nature 385, 653-656.

Steller, H. (1995). Mechanisms and genes of cellular suicide. Science 267, 1445-1449.

Veit, B., Schmidt, R., Hake, S. and Yanofsky, M. F. (1993). Maize floral development: new genes and old mutants. The Plant Cell 5, 1205-1215.

Wu, D., Wallen, H. D. and Nunez, G. (1997). Interaction and regulation of subcellular localization of CED-4 by CED-9 [see comments]. Science $\mathbf{2 7 5}$, 1126-1129.

Wyllie, A. H., Kerr, J. F. R. and Currie, A. R. (1980). Cell death: the significance of apoptosis. Int. Rev. Cytol. 68, 251-305. 